\title{
CORRECTION
}

\section{Correction to: An improved algorithm of video quality assessment by danmaku analysis}

\author{
Hanyun Zhang ${ }^{1}$. Dongliang Guo ${ }^{1} \cdot$ Liu Wei $^{2} \cdot$ Junlan Nie ${ }^{1}$ Shuo $\mathrm{Li}^{1}$
}

Published online: 16 December 2021

○) Springer-Verlag GmbH Germany, part of Springer Nature 2021

\section{Correction to: Multimedia Systems}

https://doi.org/10.1007/s00530-021-00858-7

In the original publication of the article, the third author affiliation was erroneously published; the correct affiliation should read as:

School of Computer Science, University of Technology Sydney, Sydney, Australia.

This has been corrected in this paper.

Publisher's Note Springer Nature remains neutral with regard to jurisdictional claims in published maps and institutional affiliations.

The original article can be found online at https://doi.org/10.1007/ s00530-021-00858-7.

Dongliang Guo

dongliangguo@ysu.edu.cn

1 Computer virtualization technology and system integration laboratory, Yanshan University, Qinhuangdao, China

2 School of Computer Science, University of Technology Sydney, Sydney, Australia 